\title{
Research on the Online Interactive Teaching Model of Internet+ Business Translation
}

\author{
Na Zhai \\ Translation Department, Xi'an Fanyi University, 710105 Xi'an, China \\ zhaina999@163.com
}

\begin{abstract}
Keywords: Internet+; business translation; interactive teaching
Abstract. The online interactive teaching model of Internet+ business translation, based on the constructivist theory and interactive teaching theory, has the advantages including resource sharing, extended teaching and convenient learning etc..All teaching links are composed of interactions between teacher and students, which can not only cultivate students' competence of business translation, but improve students' learning autonomy, cooperation and interaction as well.
\end{abstract}

\section{Introduction}

In 2012, Yu Yang, the founder of Analysys International Group, proposed the concept of "Internet+" in the fifth session of Analysys Mobile Internet Expo [1]. Later, in the 3rd meeting of China's twelve National People's Congress in 2015, Premier Li Keqiang put forward the "Internet+" action plan in the government work report for the first time [2]. Through "Internet+", China's traditional industries have achieved docking and reconstruction of its network to promote the traditional industries' combination with Internet, big data, cloud computing, thus to break into the international Internet market gradually. At the same time, the concept of "Internet+" also triggered a new revolution in Chinese education industry with the advocation of new type of Internet-based education.

In the "13th Five-Year" period, China will vigorously implement the "Internet+" action plan to support all kinds of industry innovation based on Internet, and encourage reform and innovation in education by using information technology. The Ministry of Education issued "The Ten Year Development Plan of Education Informatization(2011-2020)", proposed to promote the deep integration between information technology and higher education, to modernize the teaching contents, means and methods, to innovate the mode of talent training and to improve the quality of higher education as a whole. Under this background, the author puts forward the research on the online interactive teaching model of Internet+ business translation, which is the reconstruction of the traditional business translation teaching. In order to cultivate practical talents of business translation and build, reform or innovate the course of business translation, we must strengthen the integration between teaching and information technology for the construction and sharing of high-quality educational resources.

\section{Theoretical Basis of the Online Interactive Teaching Model of Internet+ Business Translation}

There are mainly two advanced theories served as the theoretical basis of and providing guidance to this new teaching model:

Constructivist Theory. Constructivist theory is a new learning theory proposed by Swiss educationalist and developmental psychologist J. Piaget in 1960s, which advocates the initiative, situation and sociality of learning [3]. Constructivist theory emphasizes learner- centered, which thinks that the process of knowledge acquisition comes from learner's active meaning construction rather than passive receiving of information. The teaching process must be carried out in a certain context and the teacher should choose the real situation to organize the classroom teaching, which can help students' meaning construction of learning content. In addition, Constructivist theory also emphasizes sociality of learning, i.e. the need to strengthen the exchange, communication, discussion and cooperation between the students in the learning process in order to complete a task, so that students can have more comprehensive and deeper understanding of learning knowledge. 
Reciprocal Teaching. Reciprocal teaching is a new teaching method proposed by American educational psychologist A.L. Brown and A.S. Palincsar in 1989. Its fundamental purpose is to change the traditional teacher-centered teaching mode into student-centered one. Various flexible teaching methods should be adopted according to different teaching situations. During the completion of a learning task, there should be equal communication and initiative interaction between the teacher and students [4]. Reciprocal teaching emphasizes the display of learner's initiation and pays attention to exchanges and cooperation between the learners. The teacher should play a leading role in teaching to develop students' creative thinking, stimulate students' learning interest and motivation, carry out teaching in a relaxed atmosphere, thus to enhance the teaching effect.

\section{The Advantages of the Online Interactive Teaching Model of Internet+ Business Translation}

There are two many advantages of this new teaching model reflecting in the richness of resources, interaction between teacher and students and the convenience due to its supporting technology:

Sharing of Resources. One of the greatest advantages of internet+ education is resource sharing. All of the business translation material, teaching video, translation works and extended business readings can be shared in the learning platform for students to download. Online learning is not subject to time and place, and the cyber resource is richer than traditional paper materials.

Extended Teaching. In the traditional teaching environment, students can hardly be allowed for the translation of a whole passage for limited teaching hours. In the class, the teacher is busy instructing the translation techniques and there is little time for discussions of difficult issues, summary of translation skills and exchange of translation experience, which are the essence of the course actually. Under the background of the online interactive teaching of internet+business translation, students can complete the translation business passages uploaded by the teacher before class. Through online interaction with the teacher and peers, they can constantly improve their own translation.

Learning convenience. Online learning is not restricted by time and space. Students can use computer, mobile phone or other networking devices for the learning of business translation. Online learning also support fractional learning: students can pause at any time no matter in the process of watching video or reading business translation materials. In addition, the students who is relatively slow in memory or learning can review the same teaching resources for many times.

\section{The Applicable Design of the Online Interactive Teaching Model of Internet+ Business Translation}

In order to show clearly the above mentioned advantages, the author here gives a detailed procedures of the applicable design of each teaching link in the online interactive teaching model of internet+ business translation (refer with: Fig. 1), taking one of teaching module of business translation-Translation of Product Description as an example.

The Utilization of Online Resources. The teacher can upload the teaching plan, curriculum standard, learning video (components, language features and translation skills of English product descriptions), business translation task (translation of medicine description), and supplementary reading (Bilingual electronic product brochures, cosmetic instructions, medicine descriptions, food instructions) of this unit to the online teaching system. The students are required to log on the system to watch the video, complete the business translation task and upload his or her translation works to the area for submission before class.

Real Time Online Discussion. There are too much professional knowledge in business translation, e.g. This unit's translation task - the translation of medicine instruction involves many professional vocabularies, such as: warfarin, acetazolamide, corticosteroids, methotrexate and so on. After consulting the electronic dictionary or online dictionary, the students still need to exchange or share views with peers in the online interactive areas for unified translation. Besides, the translation of medicine instruction requires the use of professional languages, such as "do not use chewable aspirin 
tablets, effervescent aspirin and aspirin in crushed tablets or gargles". Students can discuss with each other while using network to search the relevant information, thus to ensure the smooth, accurate expression, at the same time in accordance with the style of drug instructions. The real-time discussion can stimulate the students' learning enthusiasm and motivation. What's more, the cooperation and collaboration required in the interactive online learning model can help students to have better communication with their colleagues in the future.

Online Assistance from the Teacher. The teacher should monitor students' online discussion and cooperative learning all the time. If there is any difficulty that the students cannot solve even after consulting related information and discussing with peers, the teachers should appear and provide students with timely guidance to solve problems and help students overcome difficulties, thus to ensure the going-on of online teaching. The way of online communication breaks down barriers and eliminate the students' sense of tension, to make up for the deficiencies and defects of the traditional ways of communication. At the same time, online tutoring can better achieve different levels of teaching, teachers can use the online teaching system to comment and guide the translation problem of individual students.

Online Checking and Evaluation. The course of business translation takes the combination of formative and summative evaluation. Teacher will evaluate and score the students for each unit based on students' performances such as watching the video before class, completing the translation work, online interaction and collaboration. The automatic online evaluation system can be used for scoring after each unit's learning and all the scores will be averaged at the end of the learning semester as the result of summative assessment. The evaluation includes five aspects: a. the number of students' access, for a total of $10 \%$; b. online learning hours, for a total of $20 \%$ times; c. participation in the discussion, for a total of $10 \%$; $d$. the completion of online homework, for a total of $20 \%$; e. online test scores, total score of $40 \%$. Teacher can make full and perfect use of the intelligent software to give students timely evaluation and feedback based on actual teaching situation, thus to check the learning effect of students and help students' timely reflection and gradual improvement. The online monitoring and evaluating system can not only reduce the burden of the teacher, but also improve the students' competence of business translation and learning motivation.

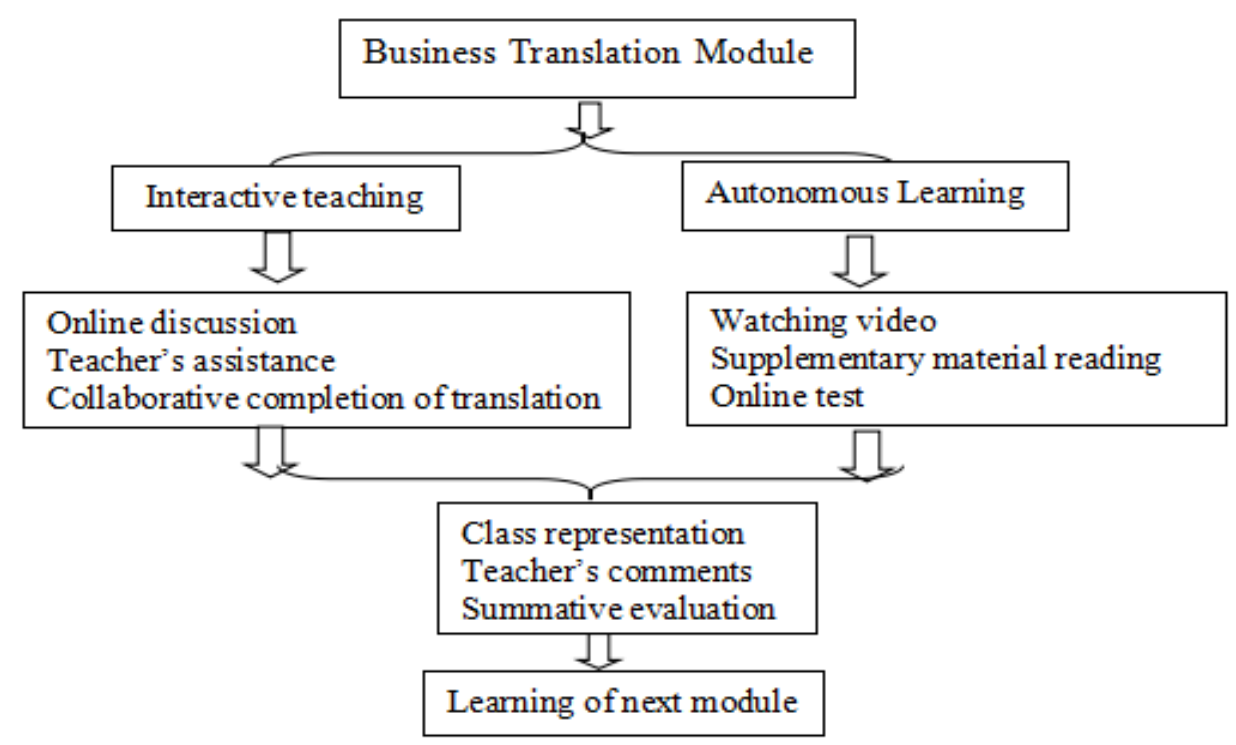

Figure 1. The Detailed Procedures of the Online Interactive Teaching Model of Internet+ Business Translation

\section{Summary}

The online interactive teaching model of Internet+ business translation online, being practice oriented, makes reform of the teaching content, mode, means for practice and evaluation based on information technology, which can solve the realistic problems in teaching to achieve the integration 
of theory and practice in business translation teaching, thus to meet the requirements of the time and profession, effectively cultivate students' ability of language usage, business translation, application of modern translation technology and the spirit of cooperation. Being student-centered, modern information technology supported and taking the cultivation of students' practical ability as the goal, this novel teaching model can advance the reform of business translation teaching significantly.

\section{Acknowledgments}

This work was financially supported by the "13th Five-Year" Project of the National Business Subject Education and Scientific Research (SKJYKT-1723).

\section{References}

[1] Information on http://www.netofthings.cn/GuoNei/2016-03/7651.html

[2] Information on http://www.netofthings.cn/GuoNei/2015-03/5505.html

[3] W. Gao, B. Y. Xu and G. Wu: The Research of Constructivist Education (Education Science Press, China 2008).

[4] Q.L. Wu: The Educational Psychology (East China Normal University Press, China 2012). 